Article

\title{
Global Latitudinal-Asymmetric Vegetation Growth Trends and Their Driving Mechanisms: 1982-2009
}

\author{
Jiafu Mao ${ }^{1, *}$, Xiaoying Shi ${ }^{1}$, Peter E. Thornton ${ }^{1}$, Forrest M. Hoffman ${ }^{2}$, Zaichun Zhu ${ }^{3}$ \\ and Ranga B. Myneni ${ }^{3}$
}

1 Environmental Sciences Division, Climate Change Science Institute, Oak Ridge National Laboratory, Oak Ridge, TN 37831, USA; E-Mails: shix@ornl.gov (X.S.); thorntonpe@ornl.gov (P.T.)

2 Climate Change Science Institute/Computer Science and Mathematics Division, Oak Ridge National Laboratory, Oak Ridge, TN 37831, USA; E-Mail: forrest@climatemodeling.org

3 Department of Earth and Environment, Boston University, 675 Commonwealth Avenue, Boston, MA 02215, USA; E-Mails: zhu.zaichun@gmail.com (Z.Z.); ranga.myneni@gmail.com (R.M.)

* Author to whom correspondence should be addressed; E-Mail: maoj@ornl.gov; Tel.: +1-865-576-7815; Fax: +1-865-574-9501.

Received: 1 February 2013; in revised form: 13 March 2013 / Accepted: 18 March 2013 / Published: 21 March 2013

\begin{abstract}
Using a recent Leaf Area Index (LAI) dataset and the Community Land Model version 4 (CLM4), we investigated percent changes and controlling factors of global vegetation growth for the period 1982 to 2009. Over that 28-year period, both the remote-sensing estimate and model simulation show a significant increasing trend in annual vegetation growth. Latitudinal asymmetry appeared in both products, with small increases in the Southern Hemisphere $(\mathrm{SH})$ and larger increases at high latitudes in the Northern Hemisphere (NH). The south-to-north asymmetric land surface warming was assessed to be the principal driver of this latitudinal asymmetry of LAI trend. Heterogeneous precipitation functioned to decrease this latitudinal LAI gradient, and considerably regulated the local LAI change. A series of factorial experiments were specially-designed to isolate and quantify contributions to LAI trend from different external forcings such as climate variation, $\mathrm{CO}_{2}$, nitrogen deposition and land use and land cover change. The climate-only simulation confirms that climate change, particularly the asymmetry of land temperature variation, can explain the latitudinal pattern of LAI change. $\mathrm{CO}_{2}$ fertilization during the last three decades was simulated to be the dominant cause for the enhanced vegetation growth. Our study, though limited by observational and modeling uncertainties, adds further insight into vegetation growth trends and environmental
\end{abstract}


correlations. These validation exercises also provide new quantitative and objective metrics for evaluation of land ecosystem process models at multiple spatio-temporal scales.

Keywords: global vegetation growth trend; LAI; CLM4; factorial simulation; evaluation; detection and attribution study

\section{Introduction}

Human induced global warming characterizes recent and foreseen projections of climate change [1]. Climate plays an important role in ecosystem functioning and is significantly regulated by terrestrial ecosystems through biogeophysical and biogeochemical feedbacks [2]. The ultimate effects of a changing climate on society, economies, and the natural environment are still unknown because of the complicated nature of the Earth system [3-5]. Continuous observation of water, energy, carbon and nutrient budgets are useful in investigating these nonlinear interactions at different spatial and temporal scales [6,7]. During recent decades, long-term global monitoring of the structural and functional characters of vegetation such as Normalized Difference Vegetation Index (NDVI), LAI and Fraction of Photosynthetically Active Radiation (FPAR) have become possible with the aid of satellite-based remote sensing instruments and associated data streams. Such fine resolution data sets over large areas have been analyzed to identify trends and variability in vegetation activity and their correlations with spatio-temporal modes of key climate variables [8,9].

Process models contain multiple measurable variables and hypothesis-oriented algorithms that can be assessed and improved through comparison with observations. Process-based land surface models represent terrestrial ecosystem dynamics and environmental feedbacks using generalized response functions [10]. They are designed to diagnose both historical and future environmental changes through interactive coupling with climate models or by non-interactive simulations driven by offline forcing agents $[11,12]$. To achieve credible results, these models must be systematically parameterized, calibrated and evaluated using independent observations at multiple spatial and temporal scales [13-15]. The rapidly increasing availability of remote sensing data has created unique opportunities for validating and improving these land surface models, especially at global and regional scales [16-20].

Multiple studies over the past three decades have investigated the global-scale relationships between climate and vegetation changes by employing available satellite datasets and ecosystem models. Generally, under warming conditions, the global enhancement of plant growth was detected and simulated particularly over the northern mid-high latitudes [21-25]. However, considerable uncertainties still exist regarding geographical distributions, pattern evolutions and external and internal factors that alter these changes. Moreover, to what extent these dynamic vegetation processes affect the magnitude and the sign of global carbon cycles is unclear [26-28].

Previous work shows that there is asymmetry in the land surface temperature trend between the northern and southern hemispheres, associated with latitudinal asymmetry in the fractions of land (highest in $\mathrm{NH}$ ) and ocean (highest in $\mathrm{SH}$ ) [29]. Such asymmetric warming characteristic raises interesting questions: (1). How is vegetation activity related to inhomogeneous land warming? (2). Can 
the response of vegetation growth to this temperature change be robustly and realistically represented by current land surface models?

Recently, a new global LAI product was derived from the NDVI version $3 \mathrm{~g}$ of Advanced Very High Resolution Radiometer (AVHRR) for Global Inventory Modeling and Mapping Studies (GIMMS) (GIMMS-LAI3g), providing an unprecedented estimate of monthly to annual distribution of vegetation dynamics over the whole globe [30]. In this study we assess the historical trends of this global remote sensing derived LAI and the prognostic LAI simulated at half-degree spatial resolution by CLM4 between 1982 and 2009. Our main objective is to evaluate both consistencies and discrepancies between the observations and CLM4 simulations in terms of the LAI trends and their relation to climate change, particularly the asymmetrically changing temperature pattern. To gain insight into various mechanisms controlling these vegetation tendencies, possible effects caused by other attributive factors such as $\mathrm{CO}_{2}$ concentration, nitrogen deposition and land use and land cover change (LULCC), are simulated and analyzed.

\section{Dataset and Methodology}

\subsection{LAI Data}

New global 15-day LAI and FPAR data sets at $8 \mathrm{~km}$ spatial resolution for the period July 1981 to December 2011 were generated from the AVHRR GMMS NDVI3g data set using an Artificial Neural Network (ANN) model. The ANN model for generating the LAI data set was trained with overlapping GIMMS NDVI3g and best-quality MODIS LAI data. The full temporal coverage of the GIMMS LAI3g data set was then generated using GIMMS NDVI3g data and the ANN model. A similar procedure was used to generate the GIMMS FPAR3g data set. These new GIMMS LAI3g and FPAR3g data sets were evaluated through direct comparisons with field data and indirectly through (a) inter-comparisons with similar satellite-data products at biome and site scales, (b) comparison against known relationships between these variables and climatic variables (temperature and precipitation), and (c) comparison to simulations from multiple dynamic vegetation models. These exercises resulted in estimates of uncertainity for these new data sets. Further details can be found in [30].

\subsection{Model and Experimental Design}

The process-based carbon-nitrogen version of CLM4 was used to prognostically generate spatially-and temporally-consistent field of LAI. CLM4 has been applied extensively over global regions at varying time scales $[19,20,31-33]$. It is designed to quantify the effects of changing climate, atmospheric $\mathrm{CO}_{2}$, nitrogen deposition and LULCC on the terrestrial ecosystem dynamics. For this study, we conducted 6 experiments at $0.5^{\circ}$ spatial resolution and in half-hour time steps on data from the years 1850 to 2009 . The transient simulation of LAI was forced by the historical CRUNCEP meteorological fields (http://dods.extra.cea.fr/data/p529viov/cruncep/) and includes historical trends in atmospheric $\mathrm{CO}_{2}$, nitrogen deposition and LULCC dynamics (simulation "ALL"). The climate-only simulation ("CLI") was designed to consider the impact of varying climate on LAI change, which used historical variations of meteorological data sets but held other non-climate factors constant at their values for 1850. A control run ("CTRL") used cyclic climate forcing, repeating years between 1901 
and 1920 with all other forcings kept constant at their 1850 levels. For the remaining simulations, the climate forcing is identical to "CTRL" while a single non-climate forcing varies in time. From the difference with "CTRL", separate contribution to LAI change from $\mathrm{CO}_{2}$ ("CO 2 "), nitrogen deposition ("NDE") and land use/land cover change ("LUC") was quantified. Further details on the forcings and experiments are documented in several other studies [19,20,33].

\subsection{Analysis}

For direct comparison with model simulations, the GIMMS-LAI3g fields were resampled onto a $0.5^{\circ}$ latitude-longitude grid with a time interval of 1 month consistent with the CLM4 outputs. Model simulations from 1982 to 2009 were selected and analyzed, corresponding to the time period for the satellite observations. The satellite LAI and each model output were masked with bare ground, defined by land cover type 2 in the Collection4 MODIS (Moderate Resolution Imaging Spectroradiometer) 1-km land cover dataset MOD12Q1, to ensure the same coverage. To facilitate analysis of biome-level LAI trend among different products, similar to Figure 1(b) in Mao et al. [20], we used the dominant Plant Functional Type (PFT) classified by CLM4 to represent the vegetation type in each half-degree grid cell. We focused on annual mean LAI and its correspondence to environmental drivers, as a commonly adopted benchmark for long-term vegetation studies [34,35]. To avoid possible errors in winter impacted by snow/ice in the satellite data, we focus our analysis on the "growing season" months. As [35], grids with $<0{ }^{\circ} \mathrm{C}$ surface air temperature based on the CRUNCEP monthly climatology between 1982 and 2009 were excluded from the annual summaries for both the satellite and model LAI. For the current analysis, the annual trend of studied variables is expressed as a percentage change relative to its climatological means.

\section{Results}

Figure 1 illustrates the 1982-2009 latitudinal LAI trends as calculated from the annual mean LAI for the satellite dataset and "ALL" simulation of CLM4 (LAI_CLM4). The observed latitudinal temperature, precipitation and land area trends and their linear fits are also shown. The asymmetry of the LAI trend for the CLM4 has a gradient of $0.08 \% /{ }^{\circ} \mathrm{N}(\mathrm{P}<0.05)(“ / \% \mathrm{~N}$ " hereafter indicates "per 28 yrs per degree of latitude increase from south to north") and is consistent with the satellite-derived LAI asymmetry of $0.09 \% /{ }^{\circ} \mathrm{N}(\mathrm{P}<0.05)$ (Table 1$)$. Both latitudinal variations show broad agreement for features of change and exhibit significantly positive correlation $\left(\mathrm{y}=\mathrm{x}+0.24, \mathrm{R}^{2}=0.44, \mathrm{P}<0.05\right)$. In terms of the global averaged LAI trend, the CLM4 produced a value $(8.5 \% / 28 \mathrm{yrs})$ slightly higher than that of remote-sensing LAI $(6.9 \% / 28 \mathrm{yrs})$. The LAI increasing trends at south of $-46^{\circ} \mathrm{S}$, north of $56^{\circ} \mathrm{N}$ and between about $-15^{\circ} \mathrm{S}-15^{\circ} \mathrm{N}$ are present but overestimated in the model. The CLM4 LAI tends also to show a downward trend at $-42^{\circ} \mathrm{S}$ to $-28^{\circ} \mathrm{S}$, while the GIMMS-LAI3g suggests a slight upward change. 
Figure 1. Latitudinal gradient of percentage change $(\% / 28 \mathrm{yr})$ in GIMMS-LAI3g, LAI_CLM4, temperature and precipitation for 1982-2009. The gray histogram indicates the latitudinal sum of land area $\left(\times 10^{6} \mathrm{~km}^{2}\right)$. Dashed lines indicate the linear fit to the latitude bands at every-5 degree.

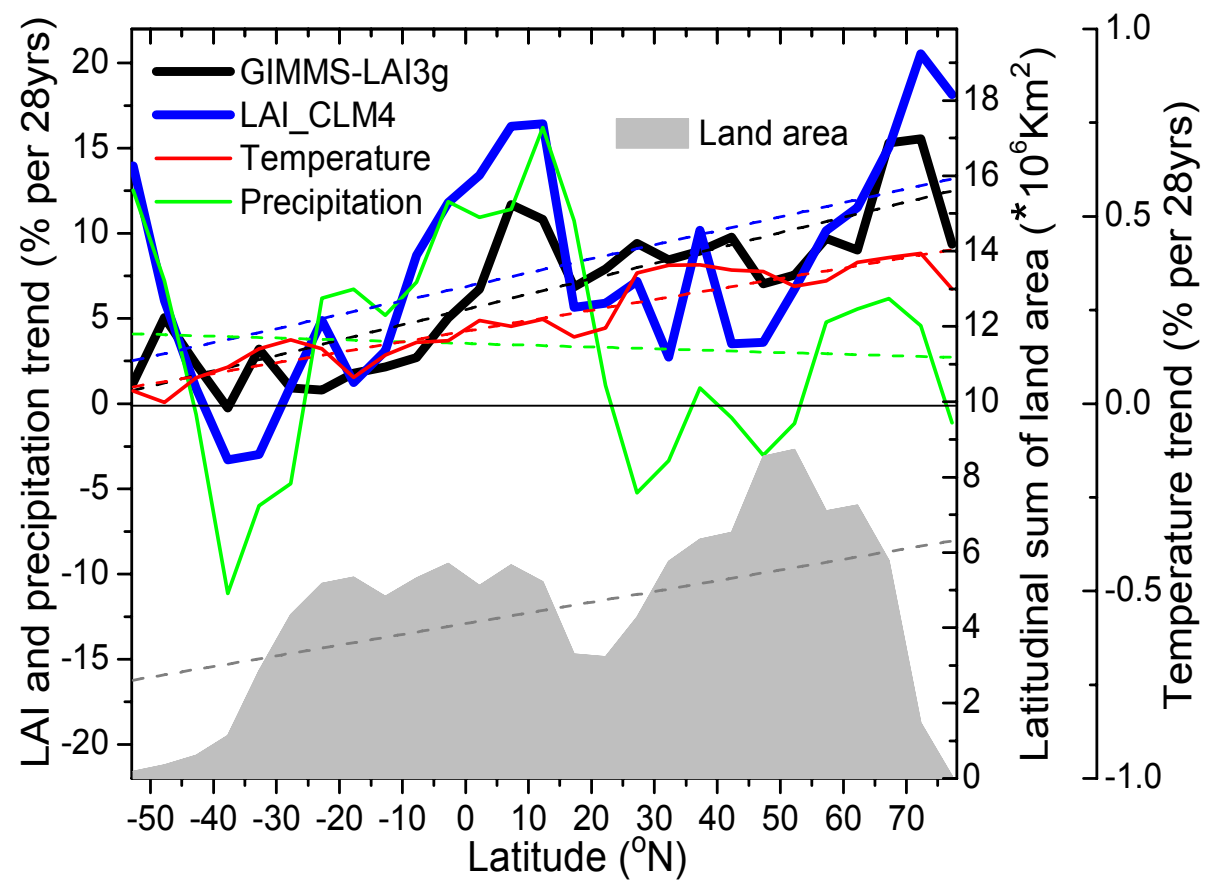

Table 1. Latitudinal trend (TREND_LAT) and spatially averaged annual trend (TREND_AVE) of LAI from Boston University (GIMMS-LAI3g), CLM4 LAI of simulation "ALL" (LAI_CLM4), CLM4 LAI of simulation "CLI" (LAI_CLI), CLM4 LAI of simulation "CO2" (LAI_CO2), CLM4 LAI of simulation "NDE" (LAI_NDE), CLM4 LAI of simulation "LUC" (LAI_LUC), annual temperature (TEMP) and annual precipitation (PREC) for the globe during the study period. Bold values represent trends with significance $(\mathrm{P}<0.05)$. The unit for TREND_LAT is $\% /{ }^{\circ} \mathrm{N}$ and for TREND_AVE is $\% / 28$ yrs.

\begin{tabular}{ccc}
\hline Variables & TREND_LAT & TREND_AVE \\
\hline GIMMS-LAI3g & $\mathbf{0 . 0 9 0 1 1}$ & $\mathbf{6 . 9 2 8 2 4}$ \\
LAI_CLM4 & $\mathbf{0 . 0 8 2 0 4}$ & $\mathbf{8 . 4 8 6 9 6}$ \\
LAI_CLI & $\mathbf{0 . 0 7 4 4 9}$ & $\mathbf{2 . 7 8 3 0 4}$ \\
LAI_CO2 & -0.0016 & 3.71356 \\
LAI_NDE & 0.00532 & 0.89213 \\
LAI_LUC & -0.00128 & 0.71303 \\
TEMP & $\mathbf{0 . 0 0 2 8 1}$ & $\mathbf{0 . 2 6 0 6 7 0 2}$ \\
PREC & -0.01059 & $\mathbf{5 . 3 1 5 3 7 4}$ \\
\hline
\end{tabular}

The latitudinal changes in precipitation are quite variable along different latitude bands and show a slight decreasing trend from the $\mathrm{SH}$ to $\mathrm{NH}$ at $-0.01 \% /{ }^{\circ} \mathrm{N}$. Compared with the satellite data, simulated latitudinal LAI trends are more significantly and positively correlated with this precipitation pattern (Table 2). Globally, the temperature trend is observed to increase over all the study latitudes (Figure 1). 
Similar to the latitudinal LAI asymmetry in both estimates, the land temperature trends also display a significant south-to-north increasing gradient at $0.003 \% /{ }^{\circ} \mathrm{N}(\mathrm{P}<0.05)$. In addition to the similarity in latitudinal gradient between the LAI and temperature trends, both LAI latitudinal trends correlate positively and significantly with the temperature changes across all latitudes (Table 2). Although a higher sensitivity to temperature change is diagnosed in satellite-derived LAI than the CLM4 LAI, these latitudinal responses of LAI to temperature inferred from different estimates are encouraging and suggest a strong control of land temperature on plant growth.

Table 2. Pearson correlations among the latitudinal trend of annual GIMMS-LAI3g, LAI_CLM4, LAI_CLI, TEMP and PREC from 1982 to 2009. Bold values mean correlations with significance $(\mathrm{P}<0.05)$.

\begin{tabular}{cccccc}
\hline \multicolumn{5}{c}{ Global } & \\
\hline & GIMMS-LAI3g & LAI_CLM4 & LAI_CLI & TEMP & PREC \\
\hline GIMMS-LAI3g & 1 & $\mathbf{0 . 6 7 7 0 4}$ & $\mathbf{0 . 6 2 2 9 6}$ & $\mathbf{0 . 7 8 8 1 1}$ & 0.1786 \\
LAI_CLM4 & & 1 & $\mathbf{0 . 9 7 1 1 5}$ & $\mathbf{0 . 3 8 4 5 6}$ & $\mathbf{0 . 6 1 5 7 3}$ \\
LAI_CLI & & & 1 & 0.31198 & $\mathbf{0 . 5 7 4 8}$ \\
TEMP & & & & 1 & -0.20715 \\
PREC & & & & & 1 \\
\hline
\end{tabular}

Figure 2 shows spatial patterns of annual linear LAI, temperature and precipitation trends during 1982 to 2009. Both observation and CLM4 show that LAI increased mainly in the NH tropics, and in the northern mid-high latitudes, particularly over Eurasia and the eastern United States. Decreasing LAI changes occurred in both estimates over central-western US, northeastern China, high latitudes of South America and eastern Australia. Important local differences are noted, however. Satellite LAI suggested downward trends around $55^{\circ} \mathrm{N}$ over the North America, north central Russia and SH tropics over Africa, while the modeled LAI showed upward changes. The change in temperature demonstrated an overall warming trend over land (Figure 2(c)). Consistent with the latitudinal trend distribution in Figure 1, more area in the $\mathrm{NH}$ than the SH experienced significant temperature increases. Precipitation trends showed pronounced regional differences with evident precipitation increase over the western Amazon, NH tropical and southern Africa, and northeastern Eurasia (Figure 2(d)). Significant precipitation decreases were observed over northeastern China and the southern part of the South America. Intriguingly, the geographical patterns of LAI change especially for the model result are generally collocated with those trends in precipitation for the study period (Figure 2(b,d)). This infers that percent change of precipitation may play an important role in affecting regional trends of vegetation growth, particularly across areas between $30^{\circ} \mathrm{S}$ and $50^{\circ} \mathrm{N}$. Plant growth displayed a closer relationship to the temperature change than the precipitation tendency at the northern mid-high latitudes. Nevertheless, in terms of the latitudinal correspondence with the LAI trend, warming, rather than precipitation change, resembles the asymmetry pattern of LAI change. This is partly because of the cancellation of precipitation effects over individual areas when precipitation trends are averaged over latitude bands. 
Figure 2. The spatial distribution pattern of the relative trend (\%/28 yr) in (a) GIMMS-LAI3g; (b) CLM4_LAI; (c) temperature; and (d) precipitation. The stippled areas represent the changes are statistically significant $(\mathrm{P}<0.05)$. The temperature trend in $(\mathrm{c})$ is scaled by multiplying 25 for direct comparison purpose.
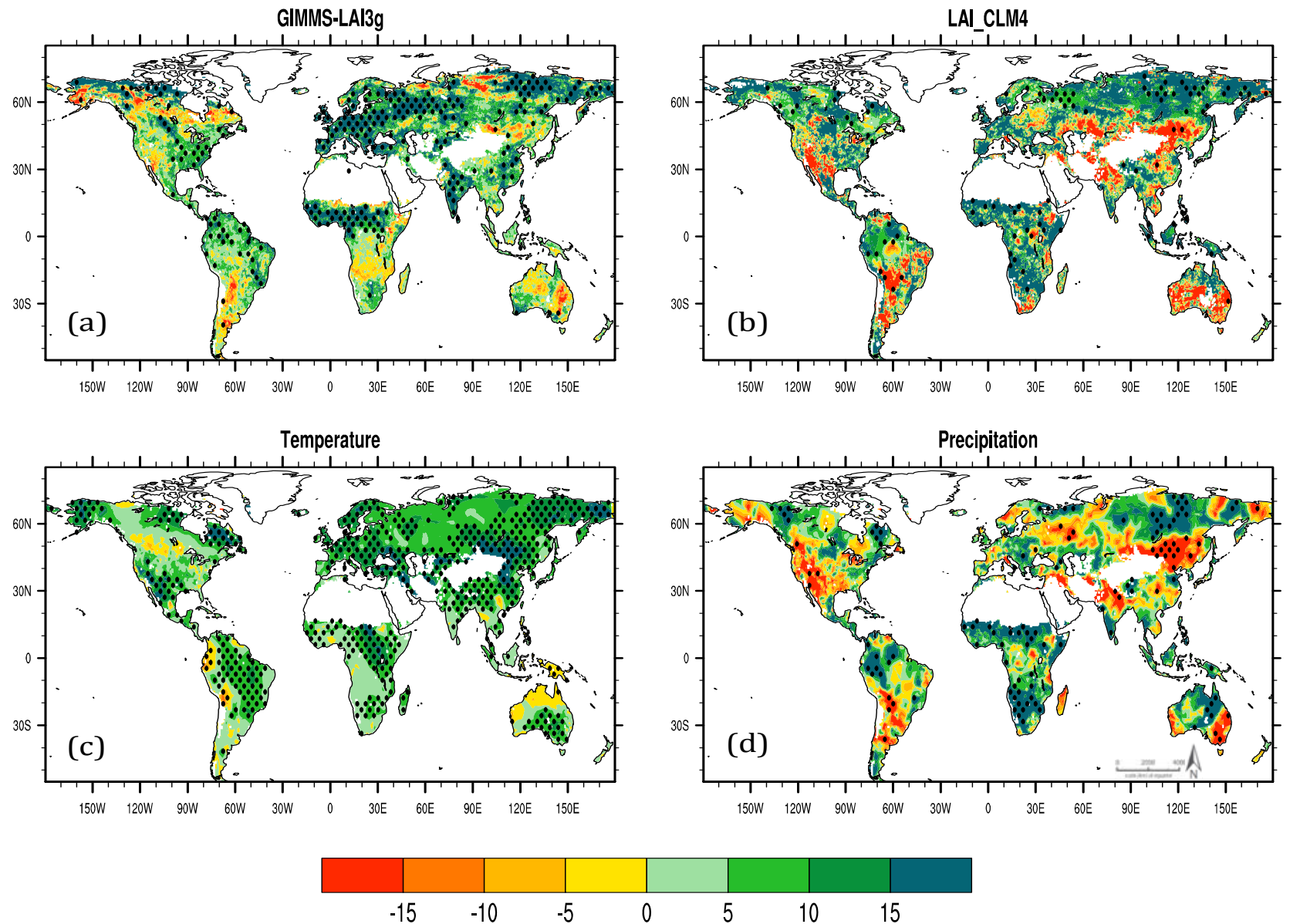

Factorial contributions to the simulated latitudinal LAI trends from the influence of $\mathrm{CO}_{2}$, nitrogen and LULCC are illustrated in Figure 3. Total LAI trend estimated by "CLI" is 2.8\%/28 yrs and lower than those of "ALL" and satellite-derived LAI trends. Positive and significant correlations between the "CLI" and "ALL" LAI trends, and the "CLI" LAI and precipitation changes were simulated implying that the precipitation generally affected the inter-latitudinal LAI trend variation in the same direction (Table 2). The climate only simulation produced a south-to-north gradient close to the "ALL" result (Table 1), which further confirmed that the LAI asymmetry trends were driven by the corresponding asymmetry in major climate variables, principally temperature. The $\mathrm{CO}_{2}$-induced LAI trends show an increasing tendency at all latitudes and a very small south-to-north slope $\left(-0.0016 \% /{ }^{\circ} \mathrm{N}\right)$. This beneficial effect of $\mathrm{CO}_{2}$ fertilization outweighed the "CLI" LAI trends and largely compensated for the climate-induced global LAI underestimation (Table 1). Both the "NDE" and "LUC" simulations produced slightly increasing global LAI but the opposite latitudinal LAI gradient (Table 1 and Figure 3(a)). High LAI changes caused by nitrogen deposition are mainly at latitudes between $15^{\circ} \mathrm{N}$ to $55^{\circ} \mathrm{N}$, and the LULCC-induced LAI relative trends varied by latitude bands.

PFT level analysis denotes that main vegetation types (with coverage area greater than $0.05 \times 10^{8} \mathrm{~km}^{2}$ ) were observed and simulated to have close positive LAI trends (Figure $3(\mathrm{~b})$ ). The 
natural variation in climate ruled the vegetation growth over broadleaf evergreen tropical tree and broadleaf deciduous boreal shrub. In contrast, the $\mathrm{CO}_{2}$ fertilization controlled the LAI trends for other PFT types, the globe and each hemisphere.

Figure 3. (a) Latitudinal gradient of percentage change $(\% / 28 \mathrm{yrs})$ in GIMMS-LAI3g, LAI_CLM4, LAI_CLI, LAI_CO2, LAI_NDE, and LAI_LUC from 1982 to 2009. The gray histogram indicates the latitudinal sum of land area $\times 10^{6} \mathrm{~km}^{2}$ ). Dashed lines indicate the linear fit to the latitude bands at every-5 degree; (b) LAI percentage trend ( $\% / 28 \mathrm{yrs}$ ) from satellite LAI and CLM4 simulations over main CLM4 plant functional types (PFTs), the globe (Global), northern hemisphere (NH), and southern hemisphere ( $\mathrm{SH}$ ). Abbreviations for PFTs are needleleaf evergreen boreal tree (NEBor Tree), broadleaf evergreen tropical tree (BETro Tree), broadleaf deciduous tropical tree (BDTro Tree), broadleaf deciduous boreal shrub (BDBor Shrub), C3 nonarctic grass (C3NA Grass), C4 grass, and corn. The yellow square denotes global and each hemisphere numbers.
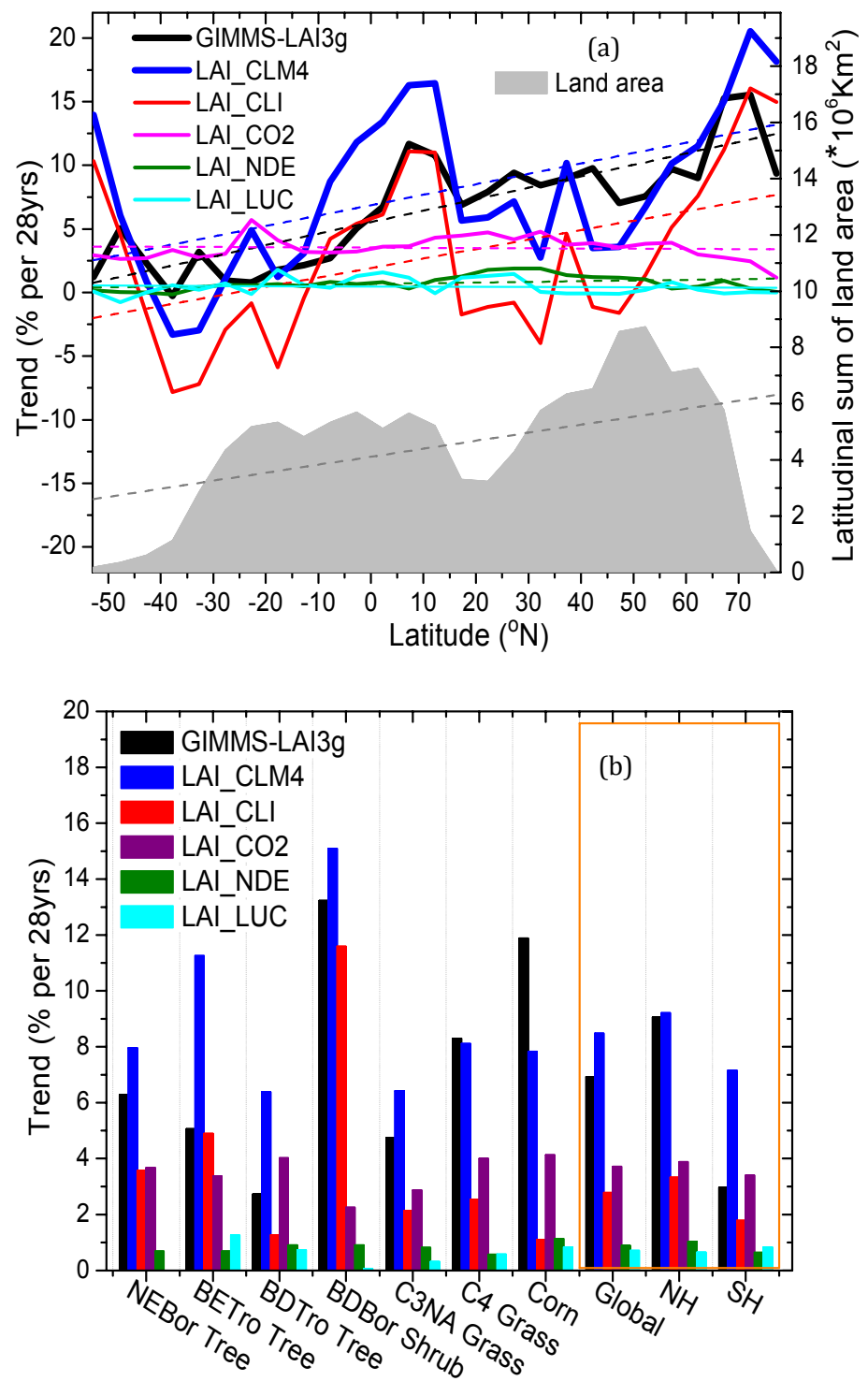

Figure 4 depicts the spatial variation of time trends in CLM4-predicted LAI ( $\% / 28 \mathrm{yrs})$ as affected by individual causative factors for the period from 1982 to 2009 . LAI trends for the simulation forced 
by observed interannual variation in climate ("CLI", Figure 4(a)) closely resemble the patterns for the simulation driven by multiple factors ("ALL", Figure 2(b)). Increasing $\mathrm{CO}_{2}$ caused increases in LAI over most regions, although isolated areas showed declining LAI, presumably as the result of increased fuel load and fire frequency in drought-prone regions (Figure 4(b)) [33]. Nitrogen deposition caused decreasing LAI trends mainly over central Europe and increasing vegetation growth over North America, central Amazon and east Eurasia (Figure 4(c)). These different responses of vegetation growth over global land areas for the "NDE" experiment followed the different trend changes of annual nitrogen deposition (Figure S4(a,b) in [19]). The LAI change simulated by "LUC" is regionally dependent, and shows substantial increases over central Europe and obvious decreases over eastern China (Figure 4(d)). Such a geographical difference of LAI trend is closely related to the extent of afforestation or deforestation (Figure $S 4(c-f)$ in [19]). The spatial pattern of dominant factor determining change in LAI, either positive or negative, is shown in Figure 4(e). Climate variability functions as a dominant controller over most areas of the globe. $\mathrm{CO}_{2}$ fertilization is the primary factor accounting for the LAI trends over some parts of the Amazon basin, central Africa and the Canadian high-latitudes around $50^{\circ} \mathrm{N}$. Land use changes over this period were a dominant, positive factor influencing LAI over parts of central Europe, southern China and tropical Asia.

Figure 4. (a-d) Spatial distribution pattern of changes in simulated annual LAI ( $\% / 28 \mathrm{yrs})$ and (e) their dominant controlling factors from 1982 to 2009. (a) experiment "CLI", (b) experiment "CO2", (c) experiment "NDE", and (d) experiment "LUC".
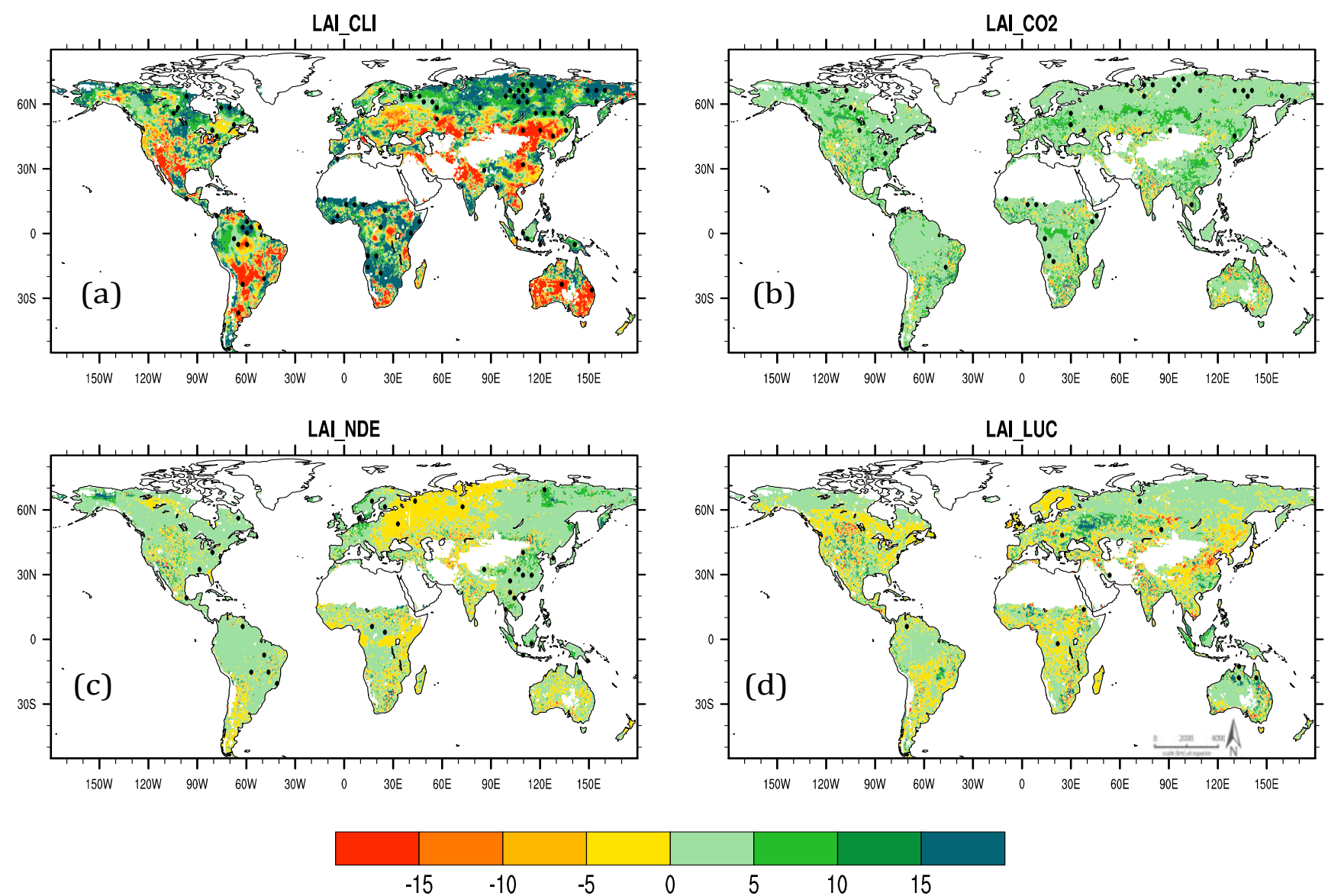
Figure 4. Cont.

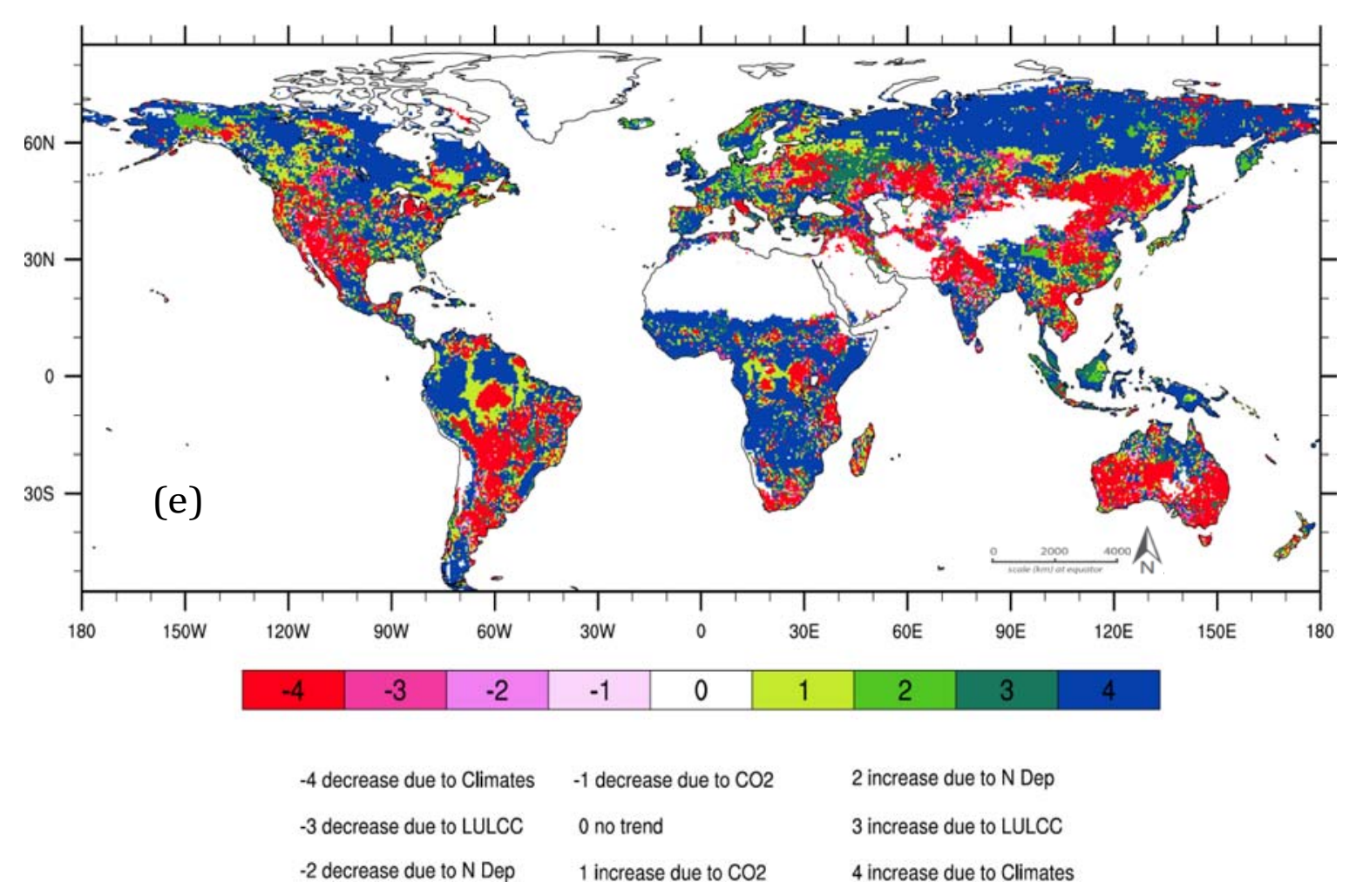

\section{Concluding Remarks}

In this study, we estimated satellite-derived and model-simulated relative change in global annual LAI from the years 1982 to 2009. The response of LAI trends to relative changes in primary climatic forcings like temperature and precipitation, changing $\mathrm{CO}_{2}$ concentration, nitrogen deposition, and LULCC were also systematically quantified. Both the remote-sensing product and CLM4 offline simulations demonstrate significant increasing trends of annual vegetation growth during the last three decades, in support of previous observations, hypotheses and modeling [19,21-25]. We find that the latitudinal distribution of LAI trends show a pattern of south-to-north asymmetry in the satellite product, as do the CLM4 "ALL" and "CLI" simulations, i.e., those forced by transient climate change. This unique feature was diagnosed to be tightly associated with the latitudinal asymmetry of the land surface temperature trend [29]. Precipitation patterns decrease this asymmetric-latitudinal LAI trend, with strong local effects. Latitudinal trend in modeled LAI is more responsive to precipitation variation than to temperature variation, while the opposite is true for the remotely sensed LAI, suggesting that CLM4 may overestimate the response of vegetation dynamics to spatial variations in precipitation, and underestimate response to spatial temperature variation [20]. Our factorial experiments indicate that, $\mathrm{CO}_{2}$ fertilization was more important than climate variation in determining the magnitude of the temporal trend in LAI at the global scale, in each hemisphere, and for most of the modeled plant functional types over our study period, in agreement with a previous study using an independently developed model [23]. This infers the significance of accurate prediction of responses of terrestrial ecosystem function and structure to $\mathrm{CO}_{2}$ fertilization with respect to future climate change. The LAI increase primarily controlled by "LUC" was simulated for tropical Asia and the Indonesian Islands in particular (Figure 4(d,e)). [36] confirms that transitions in the tropics are dominated by shifts in 
cultivation and agricultural intensification. So, these LAI changes could be driven by significant shifts in large-scale cultivation, especially in Borneo and Sumatra. CLM4 global LAI trends are biased over the tropical ecosystems between $-10^{\circ} \mathrm{S}$ and $10^{\circ} \mathrm{N}$ (Tables 1 and 2 , and Figure 3(a,b). These may be the result of poor quality forcing datasets [37,38], uncertainty in the model representation of canopy photosynthesis, and stomatal conductance [39], and/or the model ignoring the mechanism of growth limitation due to low phosphorus availability, a likely limitation in many tropical forests [40]. Uncertainties relevant to the satellite-based LAI estimate might also have contributed to the discrepancy between observed and simulated trends, notably at tropics and high latitudes of each hemisphere (Figures 1(a) and 3(a)). Over these areas, the quality of the satellite imagery dataset could be limited by known contamination issues, such as the effects of frequent cloud cover, atmospheric aerosol, snow coverage and low solar zenith angles [41,42]. A detailed description of these possible errors connected to the LAI dataset is beyond the scope of this paper, and more information can be found in [30]. Overall, our results enhance the understanding of vegetation activity and its response to varying environmental conditions at regional to global scales. Future studies should pay more attention to the detection and attribution of vegetation seasonal changes and improve the robustness of phenology and seasonality simulation. Further, the modeling and analysis of potential forcing feedbacks of terrestrial ecosystems would yield better understanding of the impacts of vegetation dynamics on global climate change and the carbon cycle.

\section{Acknowledgments}

This research is supported in part by the US Department of Energy (DOE), Office of Science, Biological and Environmental Research. Oak Ridge National Laboratory is managed by UT-BATTELLE for DOE under contract DE-AC05-00OR22725.

\section{References and Notes}

1. Hansen, J.; Ruedy R.; Sato, Mki; Lo, K. Global surface temperature change. Rev. Geophys. 2010, 48, RG4004.

2. Claussen, M.; Brovkin, V.; Ganopolski, A. Biogeophysical versus biogeochemical feedbacks of large scale land cover change. Geophys. Res. Lett. 2001, 28, 1011-1014.

3. Cox, P.M.; Betts, R.; Jones, C.D.; Spall, S.; Totterdell, I.J. Acceleration of global warming due to carbon-cycle feedbacks in a coupled climate model. Nature 2000, 408, 184-187.

4. Friedlingstein, P.; Cox, P.; Betts, R.; Bopp, L.; Von Bloh, W.; Brovkin, V.; Cadule, P.; Doney, S.; Eby, M.; Fung, I.; et al. Climate-carbon cycle feedback analysis: Results from the C4MIP model intercomparison. J. Climate 2006, 19, 3337-3353.

5. Arneth, A.; Harrison, S.; Zaehle, S.; Tsigaridis, K.; Menon, S.; Bartlein, P.; Feichter, J.; Korhola, A.; Kulmala, M.; O'Donnell, D.; et al. Terrestrial biogeochemical feedbacks in the climate system. Nat. Geosci. 2010, 3, 525-532.

6. Running, S.W.; Baldocchi, D.D.; Turner, D.P.; Gower, S.T.; Bakwin, P.S.; Hibbard, K.A. A global terrestrial monitoring network integrating tower fluxes, flask sampling, ecosystem modeling and EOS satellite data. Remote Sens. Environ. 1999, 70, 108-127. 
7. Trenberth, K.E.; Jones, P.D.; Ambenje, P.; Bojarlu, R.; Easterling, D.; Tank, A.K.; Parker, D.; Rahimzadeh, R.; Renwick, J.; Rusticucci, M.; et al. Observations: Surface and Atmospheric Climate Change. In Climate Change 2007: The Physical Science Basis, Contribution of Working Group I to the Fourth Assessment Report of the Intergovernmental Panel on Climate Change; Cambridge University Press: Cambridge, UK/New York, NY, USA, 2007; pp. 235-336.

8. Myneni, R.B.; Keeling, C.D.; Tucker, C.J.; Asrar, G.; Nemani. R. Increased plant growth in the northern high latitudes from 1981-1991. Nature 1997, 386, 698-702.

9. Nemani, R.R.; Keeling, C.D.; Hashimoto, H.; Jolly, W.M.; Piper, S.C.; Tucker, C.J.; Myneni, R.B.; Running, S.W. Climate-driven increases in global terrestrial net primary production from 1982 to 1999. Science 2003, 300, 1560-1563.

10. Pitman, A.J. The evolution of, and revolution in, land surface schemes designed for climate models. Int. J. Climatol. 2003, 23, 479-510.

11. Krinner, G.; Viovy, N.; de Noblet-Ducoudré, N.; Ogée, J.; Polcher, J.; Friedlingstein, P.; Ciais, P.; Sitch, S.; Prentice, I.C. A dynamic global vegetation model for studies of the coupled atmosphere-biosphere system. Glob. Biogeochem. Cy. 2005, 19, GB1015.

12. Dickinson, R.E.; Oleson, K.W.; Bonan, G.; Hoffman, F.; Thornton, P.; Vertenstein, M.; Yang, Z.L.; Zeng, X. The community land model and its climate statistics as a component of the community climate system model. J. Climate 2006, 19, 2302-2324.

13. Stöckli, R.; Lawrence, D.M.; Niu, G.Y.; Oleson, K.W.; Thornton, P.E.; Yang, Z.L.; Bonan, G.B.; Denning, A.S.; Running, S.W. Use of FLUXNET in the community land model development. $J$. Geophys. Res. 2008, 113, G01025.

14. Randerson, J.T.; Hoffman, F.M.; Thornton, P.E.; Mahowald, N.M.; Lindsay, K.; Lee, Y.H.; Nevison C.; Doney, S.C.; Bonan, G.; Stöckli, R.; et al. Systematic assessment of terrestrial biogeochemistry in coupled climate-carbon models. Glob. Change Biol. 2009, 15, 2462-2484.

15. Cadule, P.; Friedlingstein, P.; Bopp, L.; Sitch, S.; Jones, C.D.; Ciais, P.; Piao, S.L.; Peylin, P. Benchmarking coupled climate-carbon models against long-term atmospheric $\mathrm{CO}_{2}$ measurements. Glob. Biogeochem. Cy. 2010, 24, GB2016.

16. Oleson, K.W.; Bonan, G.B.; Schaaf, C.; Gao, F.; Jin, Y.F.; Strahler, A. Assessment of global climate model land surface albedo using MODIS data. Geophys. Res. Lett. 2003, 30, 1443.

17. Tian, Y.; Dickinson, R.E.; Zhou, L.; Zeng, X.; Dai, Y.; Myneni, R.B.; Knyazikhin, Y.; Zhang, X.; Friedl, M.; Yu, H.; et al. Comparison of seasonal and spatial variations of leaf area index and fraction of absorbed photosynthetically active radiation from Moderate Resolution Imaging Spectroradiometer (MODIS) and Common Land Model. J. Geophys. Res. 2004, 109, D01103.

18. Maignan, F.; Bréon, F.M.; Chevallier, F.; Viovy, N.; Ciais, P.; Garrec, C.; Trules, J.; Mancip, M. Evaluation of a Dynamic Global Vegetation Model using time series of satellite vegetation indices. Geosci. Model Dev. Discuss. 2011, 4, 907-941.

19. Mao, J.; Shi, X.; Thornton, P.; Piao, S.; Wang, X. Causes of spring vegetation growth trends in the northern mid-high latitudes from 1982 to 2004. Environ. Res. Lett. 2012, 7, 014010.

20. Mao, J.; Thornton, P.; Shi, X.; Zhao, M.; Post, W.M. Remote sensing evaluation of CLM4 GPP for the period 2000 to 2009. J. Climate 2012, 25, 5327-5342. 
21. Zhou, L.M.; Tucker, C.J.; Kaufmann, R.K.; Slayback, D.; Shabanov, N.V.; Myneni, R.B. Variations in northern vegetation activity inferred from satellite data of vegetation index during 1981 to 1999. J. Geophys. Res. 2001, 106, 20069-20083.

22. Lucht, W.; Prentice, I.C.; Myneni, R.B.; Sitch, S.; FriedLingstein, P.; Cramer, W.; Bousquet, P.; Buermann, W.; Smith, B. Climatic control of the high-latitude vegetation greening trend and Pinatubo effect. Science 2002, 296, 1687-1690.

23. Piao, S.; Friedlingstein, P.; Ciais, P.; Zhou, L.; Chen, A. Effect of climate and CO2 changes on the greening of the Northern Hemisphere over the past two decades. Geophys. Res. Lett. 2006, 33, L23402.

24. Piao, S.; Wang, X.; Ciais, P.; Zhu, B.; Wang, T.; Liu, J. Changes in satellite-derived vegetation growth trend in temperate and boreal Eurasia from 1982 to 2006. Glob. Change Biol. 2011, 17, 3228-3239.

25. Wang, X.; Piao, S.; Ciais, P.; Li, J.; Friedlingstein, P.; Koven, C.; Chen, A. Spring temperature change and its implication in the change of vegetation growth in North America from 1982 to 2006. Proc. Natl. Acad. Sci. USA 2011, 108, 1240-1245.

26. Angert, A.; Biraud, S.; Bonfils, C.; Henning, C.C.; Buermann, W.; Pinzon, J.; Tucker, C.J.; Fung, I. Drier summers cancel out the $\mathrm{CO} 2$ uptake enhancement induced by warmer springs. Proc. Natl. Acad. Sci. USA 2005, 102, 10823-10827.

27. Gregory, J.; Jones, C.; Cadule, P.; Friedlingstein, P. Quantifying Carbon Cycle Feedbacks. J. Climate 2009, 22, 5232-5250.

28. Arora, V.K.; Boer, G.J. Uncertainties in the 20th century carbon budget associated with land use change. Glob. Change Biol. 2010, 16, 3327-3348.

29. $\mathrm{Xu}, \mathrm{Y}$.; Ramanathan, V. Latitudinally asymmetric response of global surface temperature: Implications for regional climate change. Geophys. Res. Lett. 2012, 39, L13706.

30. Zhu, Z.; Bi, J.; Pan, Y.; Ganguly, S.; Samanta, A.; Xu, L.; Anav, A.; Piao, S.; Nemani, R.R.; Myneni, R.B. Global data sets of vegetation leaf area index (LAI)3g and Fraction of Photosynthetically Active Radiation (FPAR)3g derived from Global Inventory Modeling and Mapping Studies (GIMMS) Normalized Difference Vegetation Index (NDVI3g) for the period 1981 to 2011. Remote Sens. 2013, 5, 927-948.

31. Oleson, K.; Lawrence, D.; Gordon, B.; Flanner, M.; Kluzek, E.; Peter, J.; Levis, S.; Swenson, S.; Thornton, P.; Feddema, J. Technical Description of Version 4.0 of the Community Land Model (CLM); NCAR Technical Note NCAR/TN 478+STR; The National Center for Atmospheric Research (NCAR): Boulder, CO, USA, 2010.

32. Lawrence, D.M.; Oleson, K.W.; Flanner, M.G.; Thornton, P.E.; Swenson, S.C.; Lawrence, P.J.; Zeng, X.; Yang, Z.L.; Levis, S.; Sakaguchi, K. Parameterization improvements and functional and structural advances in version 4 of the community land model. J. Adv. Model. Earth Sys. 2011, 3, 1942-2466.

33. Shi, X.; Mao, J.; Thornton, P.E.; Hoffman, F.M.; Wilfred, M.P. The impact of climate, $\mathrm{CO}_{2}$, nitrogen deposition and land use change on simulated contemporary global river flow. Geophys. Res. Lett. 2011, 38, L08704. 
34. Sangram, G.; Samantaa, A.; Schulla, M.A.; Shabanovb, N.V.; Milesic, C.; Nemanic, R.R.; Knyazikhina, Y.; Mynenia, R.B. Generating vegetation leaf area index Earth system data record from multiple sensors. Part 2: Implementation, analysis and validation. Remote Sens. Environ. 2008, 112, 4318-4332.

35. Beck, H.E.; McVicar, T.R.; van Dijk, A.I.J.M.; Schellekens, J.; de Jeu, R.A.M.; Bruijnzeel, L.A. Global evaluation of four AVHRR-NDVI data sets: Intercomparison and assessment against Landsat imagery. Remote Sens. Environ. 2011, 115, 2547-2563.

36. Hurtt, G.; Frolking, S.; Fearon, M.; Moore, B.; Shevliakova, E.; Malyshev, S.; Pacala, S.; Houghton, R. The underpinnings of land use history: Three centuries of global gridded land use transitions, wood harvest activity, and resulting secondary lands. Glob. Change Biol. 2006, 12, 1208-1229.

37. Qian, T.; Dai, A.; Trenberth, K.E.; Oleson, K.W. Simulation of global land surface conditions from 1948 to 2004. Part I: Forcing data and evaluations. J. Hydrometeorol. 2006, 7, 953-975.

38. Thornton, P.E.; Doney, S.C.; Lindsay, K.; Moore, J.K.; Mahowald, N.; Randerson, J.T.; Fung, I.; Lamarque, J.F.; Feddema, J.J.; Lee, Y.H. Carbon-nitrogen interactions regulate climate-carbon cycle feedbacks: Results from an atmosphere-ocean general circulation model. Biogeosciences 2009, 6, 2099-2120.

39. Bonan, G.B.; Lawrence, P.J.; Oleson, K.W.; Levis, S.; Jung, M.; Reichstein, M.; Lawrence, D.M.; Swenson, S.C. Improving canopy processes in the Community Land Model version 4 (CLM4) using global flux fields empirically inferred from FLUXNET data. J. Geophys. Res. 2011, 116, G02014.

40. Yang, X.; Post, W.M. Phosphorus transformations as a function of pedogenesis: A synthesis of soil phosphorus data using Hedley fractionation method. Biogeosciences 2011, 8, 2907-2916.

41. Tucker, C.J.; Pinzon, J.E.; Brown, M.E.; Slayback, D.A.; Pak, E.W.; Mahoney, R.; Vermote, E.F.; El Saleous, N. An extended AVHRR 8-km NDVI dataset compatible with MODIS and SPOT vegetation NDVI data. Int. J. Remote Sens. 2005, 26, 4485-4498.

42. Brown, M.E.; Pinzon, J.E.; Didan, K.; Morisette, J.T.; Tucker, C.J. Evaluation of the consistency of long-term NDVI time series derived from AVHRR, SPOT-vegetation, SeaWiFS, MODIS, and Landsat ETM+ sensors. IEEE Trans. Geosci. Remote Sens. 2006, 44, 1787-1793.

(C) 2013 by the authors; licensee MDPI, Basel, Switzerland. This article is an open access article distributed under the terms and conditions of the Creative Commons Attribution license (http://creativecommons.org/licenses/by/3.0/). 